(c) American Dairy Science Association, 2005.

\title{
Large Sticky Traps for Capturing House Flies and Stable Flies in Dairy Calf Greenhouse Facilities
}

\author{
P. E. Kaufman, ${ }^{1}$ D. A. Rutz, ${ }^{1}$ and S. Frisch ${ }^{2}$ \\ ${ }^{1}$ Department of Entomology, Cornell University, Ithaca, NY 14853 \\ ${ }^{2}$ Atlantic Paste \& Glue Co., Inc., Brooklyn, NY 11232
}

\begin{abstract}
Large sticky traps were evaluated for stable fly, Stomoxys calcitrans (L.), and house fly, Musca domestica L., (Diptera: Muscidae) capture under field conditions in 5 dairy calf greenhouse facilities in New York. The farm with the highest stable fly capture had the highest house fly capture, and the farm with the lowest stable fly capture had the lowest house fly capture, suggesting that fly management practices greatly influenced trap captures. In general, stable fly populations, as reflected by increased trap capture, generally rose during the summer. Numbers of flies counted on calves did not increase, however, suggesting that the traps greatly reduced the potential stable fly pressure on the calves as the fly population increased. Estimated number of stable flies and house flies captured during this 10wk study exceeded 142,000 and 900,000, respectively. Producers were generally pleased with the trap performance and most felt that these traps reduced flies in their calf greenhouses to acceptable levels.

(Key words: Diptera, Muscidae, Musca domestica, Stomoxys calcitrans)
\end{abstract}

Abbreviation key: IPM = integrated pest management.

\section{INTRODUCTION}

The house fly, Musca domestica L., and stable fly, Stomoxys calcitrans (L.) are the primary pests of confined dairy cattle (Schmidtmann, 1985; Geden et al., 1992; Lysyk, 1993). Damage inflicted by the house fly is primarily animal and human annoyance (Schmidtmann, 1985). Similarly, the stable fly inflicts painful bites primarily on the lower legs of cattle with associated production losses (Schmidtmann, 1985; Campbell et al., 1987). An integrated program is required to manage these pests on dairy farms (Lazarus

Received June 22, 2004.

Accepted September 16, 2004.

Corresponding author: Phillip E. Kaufman; e-mail: pek4@ cornell.edu. et al., 1989; Geden et al., 1992). This has become increasingly important in areas where urban encroachment and insecticide resistance have greatly increased (Meyer et al., 1991; Kaufman et al., 2001b; Kaufman and Rutz, 2002).

A successful integrated pest management (IPM) program on dairy farms for house flies and stable flies includes weekly removal of bedding, proper choice of bedding material, use of less-toxic insecticides, release and conservation of biological control agents, and use of physical controls, such as traps (Pickens and Miller, 1987; Lazarus et al., 1989; Schmidtmann, 1991; Geden et al., 1992; Miller et al., 1993a; 1993b; Thomas et al., 1996). The incorporation of these methods is required to manage flies across the farm. However, calf holding areas are an important source of fly breeding on many farms (Meyer and Petersen, 1983; Schmidtmann, 1988; 1991) and trapping adult flies in these areas where manure management is difficult may provide relief for calves as well as reduce fly breeding.

Various types of house fly and stable fly traps have been examined (Morgan et al., 1970; Thimijan et al., 1972; Pickens and Miller, 1987; Broce, 1988; Miller et al., 1993a,b; Hogsette and Ruff, 1990). Broce (1988) and Hogsette and Ruff (1990) reported that Alsynite-based cylinder traps and Williams traps had comparable trapping efficiencies for capturing stable flies; however, house flies were captured in lower numbers in these traps (Broce, 1988). Pickens and Miller (1987) reported that baited traps and sticky pyramidal traps captured large numbers of house flies on dairy farms. Miller et al. $(1993 a, b)$ reported that the use of sticky pyramid traps reduced stable fly populations on dairy farms.

Large, plastic covered, half-hoop structures resembling greenhouses used for holding large numbers of calves are replacing individual calf hutches on New York dairy farms. Within these structures, individual animals can be separated easily with fencing. The benefits of using these structures (greenhouses) are numerous (easier animal handling, healthier calves, and easier cleanup). The potential exists, however, for producing large numbers of house flies and stable flies.

The Spider Web (Atlantic Paste \& Glue Co., Inc, Brooklyn, NY) is a high-capacity sticky trap that cap- 


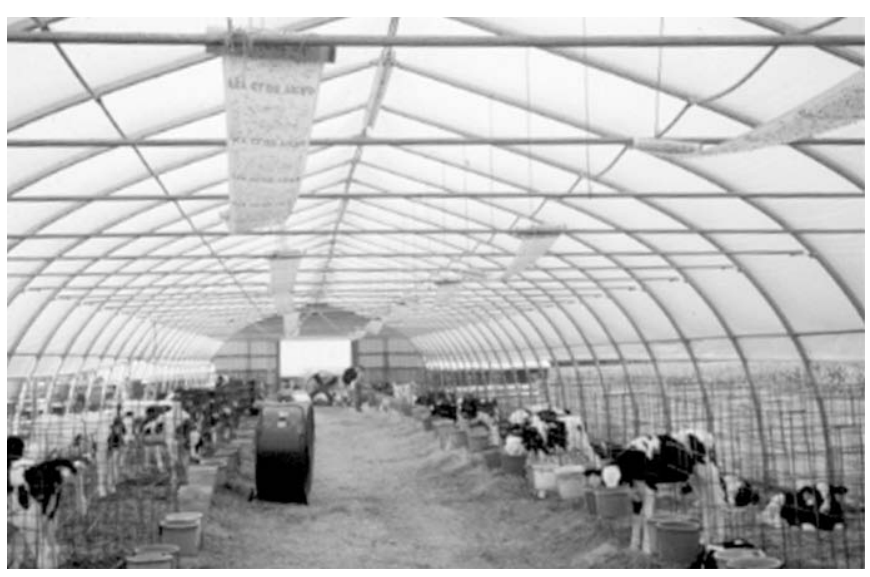

Figure 1. Dairy calf greenhouse with Spider Web sticky traps (Atlantic Paste \& Glue, Brooklyn, NY) positioned in the rafters.

tures exceptionally large numbers of house flies when flies are at high densities. This $(30 \mathrm{~cm}$ wide $\times 7.3 \mathrm{~m}$ long) trap was designed to allow a variable length of exposure and contains several house fly attractants. Initial evaluation of the Spider Web trap documented its ability to attract and capture large numbers of stable flies in dairy calf greenhouses (P. E. Kaufman, unpublished data, 1998). Kaufman et al. (2001a) documented reduced house fly densities in poultry facilities using the trap. In that study, however, dust accumulation reduced the capture potential of the trap. The design of the greenhouse provides a sheltered environment with lower dust levels than those found in poultry facilities. Placement of the Spider Web trap in these facilities could result in removal of large numbers of house flies and stable flies with minimal impact on normal farm operations.

To date, no research has been published on the effectiveness of this trap in dairies. In the current study, we evaluated the effectiveness of the Spider Web trap in capturing house flies and stable flies in 5 dairy calf greenhouses in New York.

\section{MATERIALS AND METHODS}

This study was conducted in 5 New York dairy calf greenhouses in northern Tompkins and southern Cayuga counties. Greenhouses were plastic covered, halfhoop structures of similar design having calves penned individually or in small groups on opposite sides of the greenhouse with a central alley used for animal access (Figure 1). During the study, the doors at each end of the greenhouse were open and the sides were rolled up to allow for increased ventilation. The study was conducted from July 12 to September 17, 1999 (10 wk). Stable fly densities were documented using calf leg
Table 1. Number of Spider Web (Atlantic Paste \& Glue, Brooklyn, NY) sticky traps placed and calves housed in greenhouses on 5 New York dairy farms in 1999.

\begin{tabular}{lcl}
\hline Farm $^{1}$ & No. of traps & \\
\hline A & 9 to 15 & No. of calves \\
B & 4 to 7 & 44 to 64 \\
C & 15 to 20 & 16 to 24 \\
D & 8 to 12 & 65 to 87 \\
E & 10 to 15 & 36 to 50 \\
\hline
\end{tabular}

${ }^{1}$ Farm A and C: greenhouse $10 \times 62 \mathrm{~m}$, maximum of 20 traps; Farm B: greenhouse $10 \times 31 \mathrm{~m}$, maximum of 10 traps; Farm D: greenhouse $10 \times 37 \mathrm{~m}$, maximum of 12 traps; Farm E: greenhouse $10 \times 46 \mathrm{~m}$, maximum of 15 traps.

${ }^{2}$ Number of Spider Web traps placed in facilities on Monday. Only $3 \times 0.3 \mathrm{~m}$ of the traps were exposed.

counts made each Monday and Friday by counting flies on the lower legs of 15 calves per greenhouse.

Spider Web traps were positioned horizontally and attached to the rafters, $2.5 \mathrm{~m}$ above the ground in all greenhouses (Figure 1). The number of traps placed in each greenhouse was based on the label directions for these traps that suggested $6.1 \mathrm{~m}$ of trap ( $0.3 \mathrm{~m}$ wide) be placed for every $56 \mathrm{~m}^{2}$ of building. Traps were stretched to $3 \mathrm{~m}$ because longer distances were not stable. Each Monday, the greenhouse percentage capacity was determined by dividing the number of calves present by the total number of pens. The number of traps placed was determined by percentage capacity. Thus, the number of traps placed varied weekly (Table 1). Traps were not placed and data were not collected during wk 3 because of trap unavailability.

Following a 4-d exposure, traps were taken down and stable fly calf leg counts recorded. After a 3-d absence of sticky traps, new traps were installed and leg counts taken. This provided an alternating 4- and 3-d exposure: no exposure period, respectively.

All traps were returned to the laboratory and the numbers of house flies and stable flies on each trap were counted. To determine the numbers of flies captured, each trap was unrolled and suspended such that both the top and bottom of the trap could be observed from the side. Trap exposures were measured to determine the exact length presented. To estimate the numbers of flies on a trap, transparent acetates $(7.6 \times 28$ $\mathrm{cm}$ ) were positioned on opposite sides of the trap and flies observed through the acetate were identified and counted. Acetates were positioned randomly with 5 areas counted on each trap. For each fly species, the numbers of flies per side of each trap were estimated by multiplying the length of each trap $(\mathrm{cm})$ by the average number of flies/cm per respective side. Total trap capture was estimated by summation of the fly counts on both sides. 


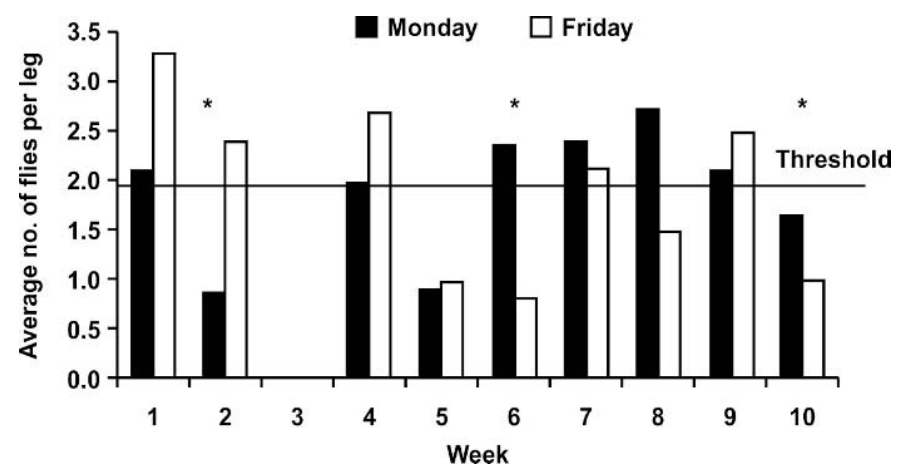

Figure 2. Average number of adult stable flies counted per calf leg at 5 New York dairy calf greenhouses. *Indicates $(P \leq 0.05)$ differences between treatments.

On farms where adult flies were abundant, but where fly breeding was not found in the calf areas, an intensive, farm-wide search was conducted to locate the onfarm breeding source of the observed adult flies. This involved examining typical fly breeding sites such as silage areas, maternity pens, sick animal pens, feed preparation sites, manure storage areas, and nontypical sites on the property that might harbor fly breeding.

Stable fly leg count data were normalized using a log $(\mathrm{x}+1.5)$ transformation and examined by study week using a 2-way ANOVA with dairy farm, count day, and the interaction effect farm $\times$ day in the linear model (SAS Institute, 1996).

An analysis of the house fly and stable fly capture was done separately using the same statistical model for each fly species. A multifactorial ANOVA was conducted on the total fly capture data with week of collection, farm, and the week $\times$ farm interaction effect in the linear model (SAS Institute, 1996). The least square means (LSMeans) procedure using a Tukey's mean separation test was used to identify differences between farms. Untransformed means are presented in all figures.

\section{RESULTS AND DISCUSSION}

The greatest number of stable flies counted on animal legs occurred during the first week of the study (Figure 2). During wk 1, 2, 4, 5, and 9, numerically more flies were counted on Friday (following trap presence) than on the previous Monday (traps absent Friday, Saturday, and Sunday). However, only during wk 2 were the levels of flies found to be significant $(P<0.05)$. In contrast, more $(P<0.05)$ flies were observed on animals during wk 6 and 10 on Mondays when traps were not present, suggesting that during those weeks the trap captured significant numbers of flies in the greenhouses.

Mean numbers of stable flies captured per trap per week on each farm are presented in Figure 3. This figure documents the differences observed between farms and may be an indication of fly management practices, such as proper disposal of refused water and choice of bedding material. Overall, the most $(P<0.001)$ stable flies were captured on farms $\mathrm{C}$ and $\mathrm{E}$, whereas stable fly capture was lowest on farm D. In general, stable fly

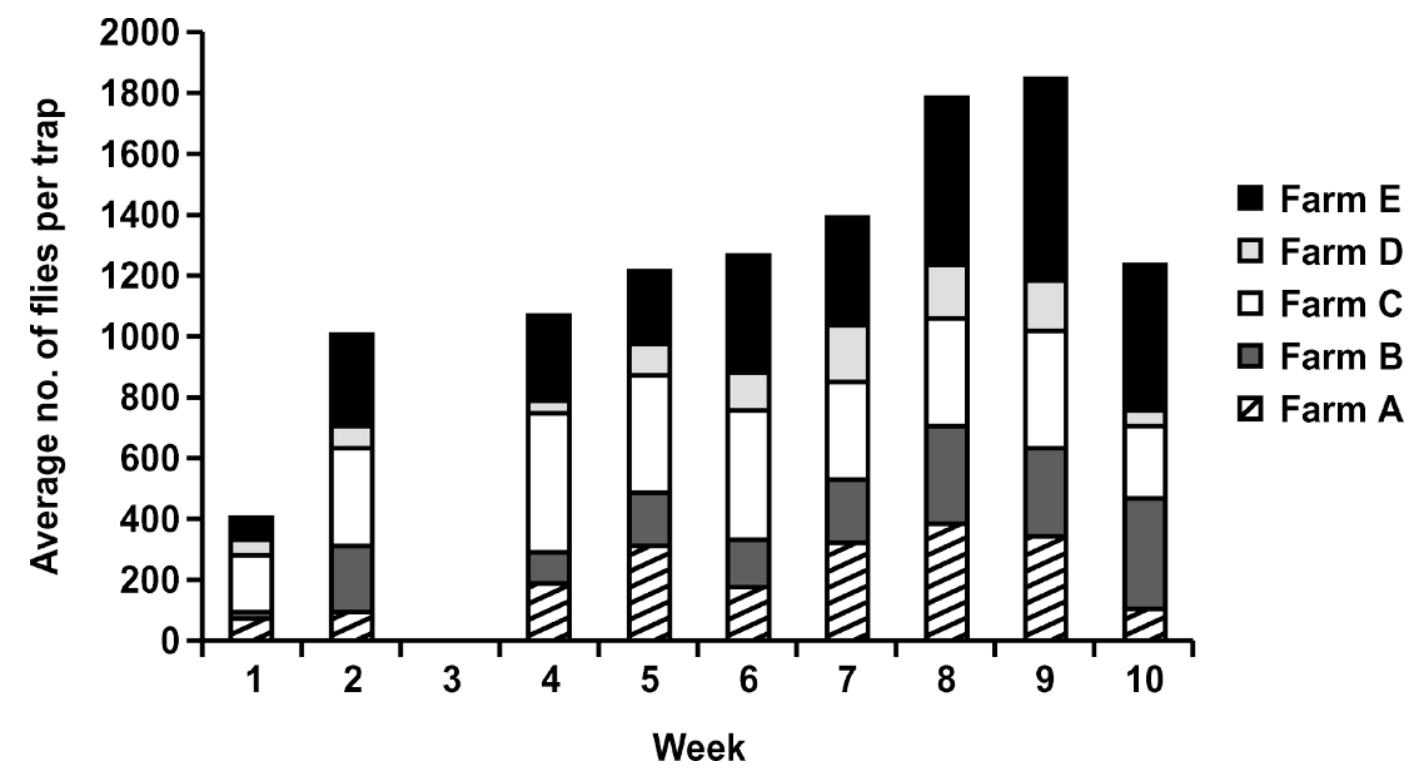

Figure 3. Estimated mean number of stable flies captured during a 4-d exposure per week per Spider Web sticky trap (Atlantic Paste \& Glue, Brooklyn, NY) at each of 5 New York dairy calf greenhouses. 


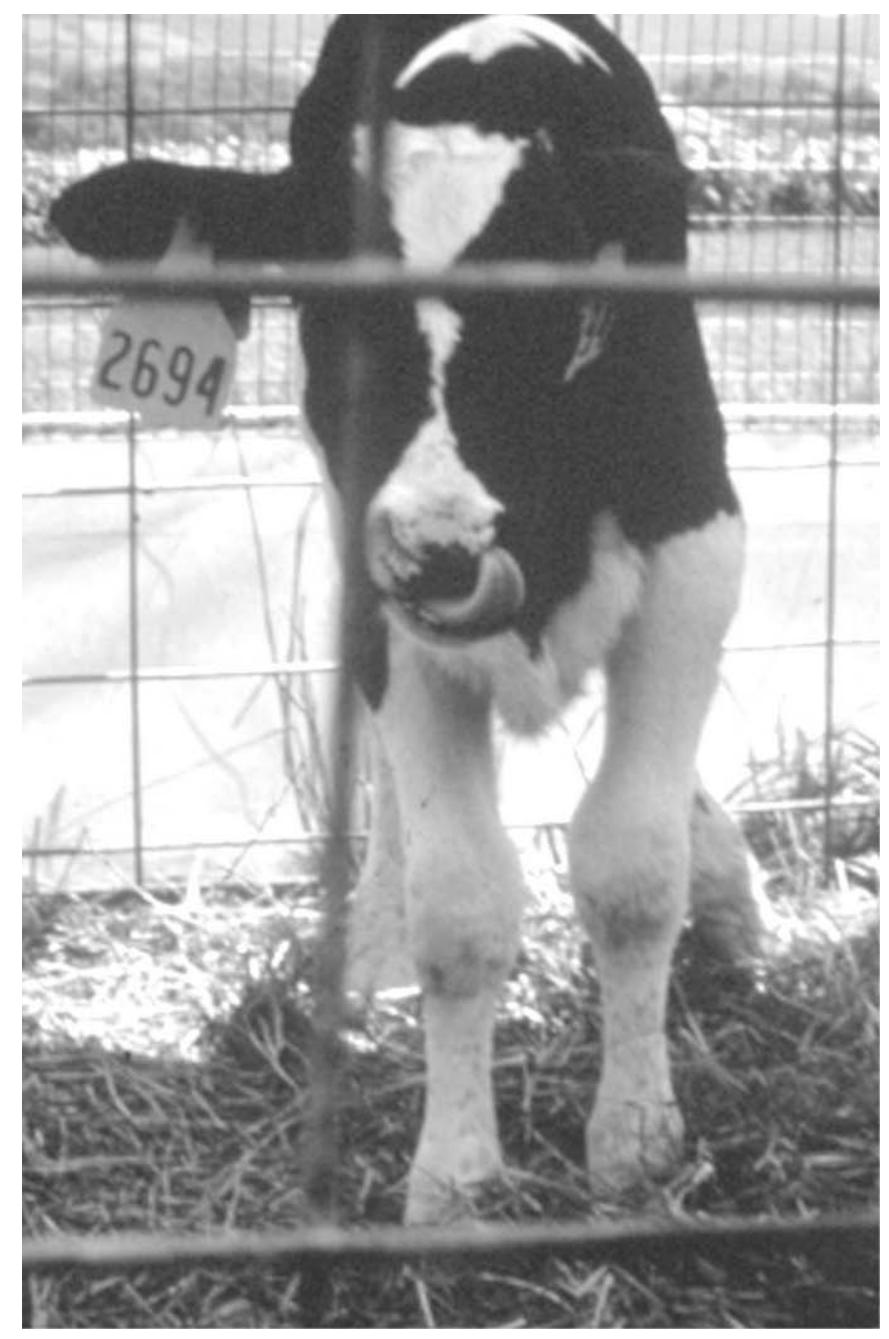

Figure 4. Dairy calf housed in greenhouse displaying damage inflicted on lower legs by stable fly feeding.

populations, as reflected by increased trap capture, rose during the summer, with the most $(P<0.01)$ flies captured on traps during wk 8 and 9 , encompassing the dates of August 30 to September 03 and September 06 to 10 (Figures 2 and 3). As documented in Figure 2, however, the numbers of flies counted on calves did not increase, suggesting that the trap was able to capture increasingly greater numbers of stable flies while maintaining the pressure of feeding flies nearly constant.

The mean number of stable flies captured per trap in the current study appeared to be much lower than the 10,480 stable flies captured in a preliminary study conducted in 1998. In the preliminary evaluation, one Spider Web trap was placed for $14 \mathrm{~d}$ at the end of the summer in a calf greenhouse (farm A) with a large stable fly population. The current study represents the use of many traps placed for only $4 \mathrm{~d}$. To make a compar- ison, we estimated the total numbers of stable flies captured at farm A over the same 2 wk of September (same farm and calendar dates as the preliminary study). The total number of stable flies captured during wk 9 and 10 (September 06 to 09 and 13 to 16) at farm A was 5556. This represented 8 of the 14 potential trapping days. Therefore, a mathematical calculation estimated the numbers of flies that might have been captured if the rate of capture held constant: [(5556 $\div$ $8) \times 14]=$ the number of stable flies captured in $14 \mathrm{~d}$. This value equals 9723 . This number is similar to the value from 1998 and suggests that a similar fly capture may be possible at a lower trap density.

Before the start of the current trial, dairy calves held in these greenhouses were noticeably affected by stable fly feeding (loss of hair and formation of scabs on the lower legs; Figure 4). Following placement of the Spider Web trap, these conditions were not observed. The economic threshold for stable flies is $<2$ stable flies per leg on beef heifers (Campbell et al., 1987). During wk 1, 2, 4 , and 6 to 9 , fly leg counts indicated that stable fly densities were above the threshold established by Campbell et al. (1987; Figure 2).

Total number of stable flies captured per week on all farms exceeded 10,000 per 4-d period in 8 of the $9 \mathrm{wk}$. In our study, an average of 51 calves was housed per facility during wk 9, with an average of 11.5 traps placed per farm. During that week an estimated 4,866 stable flies were captured per farm, yielding 95 flies per animal removed from the facilities. Certainly all of these flies would not be feeding at one time, however, the large number of flies captured indicates relief for the calves. An estimated 142,240 stable flies were captured during the trial using 563 traps.

Average numbers of house flies captured per trap per week on each farm are presented in Figure 5. Traps placed at farms $B$ and $C$ captured the most $(F=10.80$, $\mathrm{df}=443, P<0.001$ ) house flies. As was observed with the stable fly data, traps placed at farm $\mathrm{D}$ captured the fewest house flies.

In 7 of the $9 \mathrm{wk}$, the number of house flies captured on all farms exceeded 80,000 flies per 4 -d sampling period. Differences in weekly house fly capture were not observed. Following a peak capture during wk 4 (131,000 on 55 traps), and other than a 2 -wk peak (wk 8 and 9), house fly numbers declined during the summer. The rapid increase in fly numbers indoors at dairy facilities regularly occurs in New York as the summer season approaches fall, wk 8 and 9 in our study (August 30 to September 12), because flies move into warmer barns. An estimated total of 903,245 house flies were captured during the trial using 563 traps.

In the current study, traps were placed at a rate determined by the numbers of calves in the facility. 


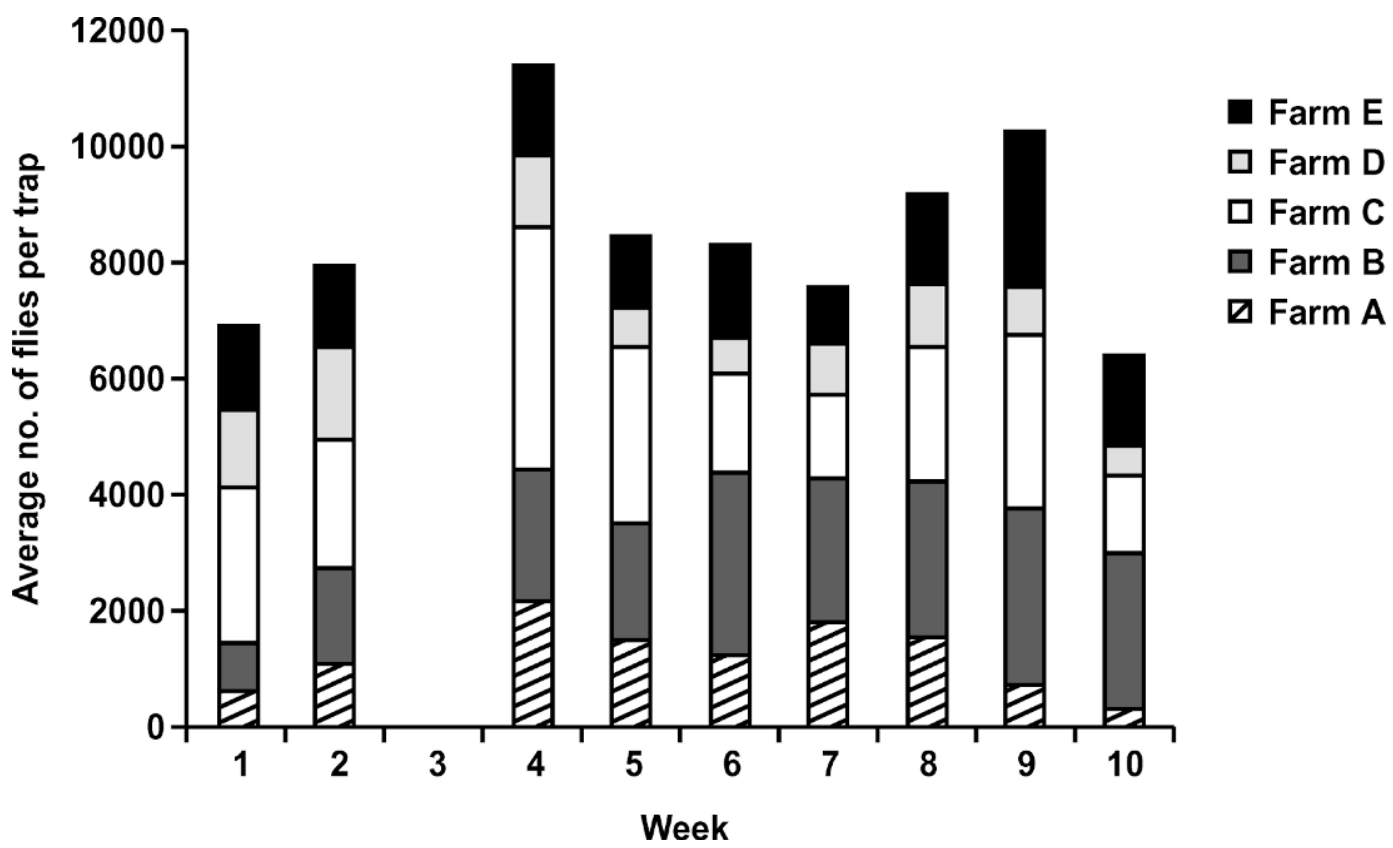

Figure 5. Estimated mean number of house flies captured during a 4-d exposure per week per Spider Web sticky trap (Atlantic Paste \& Glue, Brooklyn, NY) at each of 5 New York dairy calf greenhouses.

This placement level did not take into account the fly breeding on farms and this is probably the primary reason for differences in capture rate. Availability of breeding substrate within calf greenhouses certainly varied between farms, but breeding outside the calf facility also undoubtedly influenced fly capture, as was observed with farm B. This farm had the driest manure pack and the fewest numbers of calves, which should have been reflected in fewer flies. This farm, however, consistently had the highest numbers of house flies on traps (Table 1; Figure 5). Fly breeding was all but absent in the calf greenhouse and subsequent farm-wide searches for fly breeding failed to locate an on-farm breeding source that may have been responsible for the high numbers of house flies observed on this farm.

In all facilities, storm-generated winds were the cause of most problems associated with the effective use of the Spider Web trap, such as folding onto themselves, unrolling, and occasionally tearing. In general, producers were very pleased with the trap and most felt that the traps reduced fly densities in their calf greenhouses to acceptable levels. On farms in which fly densities were greatest, producers felt that calves and employees were less bothered by flies when traps were present (during the week) than on weekends (Friday, Saturday, and Sunday), when traps were absent. All producers indicated that they would be willing to place traps in their facilities and expose a fresh area when needed such as when traps become filled with flies or dust.
Our study was conducted to determine the efficacy of the Spider Web trap in capturing house flies and stable flies in calf greenhouses. To do this, we removed traps after only $4 \mathrm{~d}$. In practice, producers will not do this, and would capture considerably more flies per trap by having traps available at all times. If a constant fly capture rate were applied to the data in our study, perhaps as many as 248,000 stable flies and $1,580,000$ house flies could have been removed from these 5 farms. Kaufman et al. (2001a) documented both the large capture potential and the rapid decrease in efficacy (due to dust) of the Spider Web trap in poultry facilities, relegating it to fly outbreak situations. This was not the case in calf greenhouses, in which traps were still very sticky when removed. As a result, these traps should work effectively as a continual-use fly management tactic. In the current study, producers were not encouraged to practice fly management, therefore, fly breeding areas were generally abundant, with the exception of farm B.

As stressed in all IPM programs, there is no "silver bullet" to fly management. The Spider Web trap seems to have the ability to remove large numbers of flies with minimal impact on normal farming operations. Dairy producers need to use additional methods of fly management because producers will probably never be satisfied with the Spider Web trap as their sole "fly control" tactic. Therefore, manure management remains the key to successful fly management. Historically, IPM prac- 
tices have consistently provided excellent returns to producers for their fly management efforts. The inclusion of the Spider Web trap as a new IPM tool should further enhance these efforts.

\section{ACKNOWLEDGMENTS}

We thank S. Long, G. Howser, C. Bialowas, E. Gay, J. Yost, and E. Homan for their assistance with this study, and the dairy producers for allowing us to use their facilities.

\section{REFERENCES}

Broce, A. B. 1988. An improved Alsynite trap for stable flies, Stomoxys calcitrans (Diptera: Muscidae). J. Med. Entomol. 25:406-409.

Campbell, J. B., I. L. Berry, D. J. Boxler, R. L. Davis, D. C. Clanton, and G. H. Deutscher. 1987. Effects of stable flies (Diptera: Muscidae) on weight gain and feed efficiency of feedlot cattle. J. Econ. Entomol. 80:117-119.

Geden, C. J., D. A. Rutz, R. W. Miller, and D. C. Steinkraus. 1992. Suppression of house flies (Diptera: Muscidae) on New York and Maryland dairies using releases of Muscidifurax raptor (Hymenoptera: Pteromalidae) in an integrated management program. Environ. Entomol. 21:1419-1426.

Hogsette, J. A., and J. P. Ruff. 1990. Comparative attraction of four different fiberglass traps to various age and sex classes of stable fly (Diptera: Muscidae) adults. J. Econ. Entomol. 83:883-886.

Kaufman, P. E., D. A. Rutz, and S. Frisch. 2001a. Sticky traps for large scale house fly (Diptera: Muscidae) trapping in New York poultry facilities. J. Agric. Urban Entomol. 18:43-49.

Kaufman, P. E., J. G. Scott, and D. A. Rutz. 2001b. Monitoring insecticide resistance in house flies from New York dairies. Pest Manag. Sci. 57:514-521.

Kaufman, P. E., and D. A. Rutz. 2002. Susceptibility of house flies (Diptera: Muscidae) exposed to commercial insecticides on painted and unpainted plywood panels. Pest Manag. Sci. 58:174-178.

Lazarus, W. F., D. A. Rutz, R. W. Miller, and D. A. Brown. 1989. Costs of existing and recommended manure management practices for house fly and stable fly (Diptera: Muscidae) control on dairy farms. J. Econ. Entomol. 82:1145-1151.

Lysyk, T. J. 1993. Adult resting and larval developmental sites of stable flies and house flies (Diptera: Muscidae) on dairies in Alberta. J. Econ. Entomol. 86:1746-1753.

Meyer, J. A., and J. J. Petersen. 1983. Characterization and seasonal distribution of breeding sites of stable flies and house flies (Diptera: Muscidae) on eastern Nebraska feedlots and dairies. J. Econ. Entomol. 76:103-108.

Meyer, J. A., T. A. Shultz, C. Collar, and B. A. Mullens. 1991. Relative abundance of stable fly and house fly (Diptera: Muscidae) pupal parasites (Hymenoptera: Pteromalidae; Coleoptera: Staphylinidae) on confinement dairies in California. Environ. Entomol 20:915-921.

Miller, R. W., D. A. Rutz, L. G. Pickens, and C. J. Geden. 1993a. Evaluation of traps and the parasitoid Muscidifurax raptor Girault and Sanders to manage house flies and stable flies on dairy farms. J. Agric. Entomol. 10:9-19.

Miller, R. W., L. G. Pickens, and W. E. Potts. 1993b. Comparison of traps and an integrated program to manage house flies and stable flies on dairy farms. J. Agric. Entomol. 10:189-196.

Morgan, N. O., L. G. Pickens, and R. W. Thimijan. 1970. House flies and stable flies captured by two types of traps. J. Econ. Entomol. 63:672-673.

Pickens, L. G., and R. W. Miller. 1987. Techniques for trapping flies on dairy farms. J. Agric. Entomol. 4:305-313.

SAS Institute. 1996. User's Guide. Statistics. Version 6 ed. SAS Inst., Inc., Cary, NC

Schmidtmann, E. T. 1985. Arthropod pests of dairy cattle. Pages 223238 in Livestock Entomology. R. E. Williams, R. D. Hall, A. B. Broce, P. J. Scholl, ed. John Wiley and Sons, New York, NY.

Schmidtmann, E. T. 1988. Exploitation of bedding in dairy outdoor calf hutches by immature house and stable flies (Diptera: Muscidae). J. Med. Entomol. 25:484-488.

Schmidtmann, E. T. 1991. Suppressing immature house and stable flies in outdoor calf hutches with sand, gravel, and sawdust bedding. J. Dairy Sci. 74:3956-3960.

Thimijan, R. W., L. G. Pickens, N. O. Morgan, and R. W. Miller. 1972. House fly capture as a function of number of traps in a dairy barn. J. Econ. Entomol. 65:876-877.

Thomas, G. D., S. R. Skoda, D. R. Berkebile, and J. B. Campbell. 1996. Scheduled sanitation to reduce stable fly (Diptera: Muscidae) populations in beef cattle feedlots. J. Econ. Entomol. 89:411-414. 